\title{
Continuous evaluation of participants' perceptions of impact: Applying a boundary object in organisational-level interventions
}

Ipsen, Christine; Gish, Liv; Poulsen, Signe; Kirkegaard, Marie Louise

Published in:

Human Factors and Ergonomics In Manufacturing

Link to article, DOI:

10.1002/hfm.20830

Publication date:

2020

Document Version

Peer reviewed version

Link back to DTU Orbit

Citation (APA):

Ipsen, C., Gish, L., Poulsen, S., \& Kirkegaard, M. L. (2020). Continuous evaluation of participants' perceptions of impact: Applying a boundary object in organisational-level interventions. Human Factors and Ergonomics In Manufacturing, 30(3), 149-164. https://doi.org/10.1002/hfm.20830

\section{General rights}

Copyright and moral rights for the publications made accessible in the public portal are retained by the authors and/or other copyright owners and it is a condition of accessing publications that users recognise and abide by the legal requirements associated with these rights.

- Users may download and print one copy of any publication from the public portal for the purpose of private study or research.

- You may not further distribute the material or use it for any profit-making activity or commercial gain

- You may freely distribute the URL identifying the publication in the public portal 


\title{
Continuous evaluation of participants' perceptions of impact: Applying a boundary object in organisational-level interventions
}

\begin{abstract}
Workplaces across Europe experience increasing problems with work-related strain and stress. Consequently, they are confronted with the need for stress-preventive interventions that target the sources of stress. A matter of current debate is how to continuously evaluate an organisationallevel intervention and gain insight into progress and participants' perceptions of its impact; however, empirical data are lacking. Therefore, we conducted a qualitative study in three workplaces - two in information technology (IT) and one in manufacturing - to explore the design, evaluation process, perceived impact and employees' experiences with the continuous use of a physical evaluation tool (visualisation object) during an organisational-level intervention process. We conducted observations, surveys, semi-structured interviews and chronicle workshops across all three workplaces. Overall, the results showed that the visualisation object proved successful as a tool to explicate and combine participants' perceptions of impact. The evaluation process also clarified that participants initially had different understandings of the intervention's purpose. However, the study also showed that the visualisation object facilitated a dialogue among participants, converging the different understandings to create a shared understanding and compliance of purpose. Finally, the respondents reported that the evaluation tool acted as a collective reminder of the intervention and the related changes. We conclude the study by providing recommendations for future evaluations of participatory organisational-level interventions.
\end{abstract}




\section{Key words: Interventions, Evaluation, Boundary object, SMEs, Visualisation}

\section{INTRODUCTION}

To solve work-related stress problems and reduce associated economic losses, numerous studies have investigated the implementation of primary interventions (Bauer \& Jenny, 2013; Mellor et

al., 2011; Nielsen, Raymond, Holten, \& González, 2010; Sørensen \& Holman, 2014; Westgaard \& Winkel, 2011). The aim of a primary intervention is to eliminate or reduce the sources of stress (i.e. stressors) in the workplace by implementing changes at the organisational level (Murphy, 1988; Murphy \& Sauter, 2003), for example, by reorganising lines of authorities, restructuring organisational units and redesigning job tasks and roles (Elkin \& Rosch, 1990).

Discussion in organisational intervention studies that target the sources of work-related stress (Kompier \& Kristensen, 2000; Murphy, 1988) has focused on the organisational conditions required to ensure that an organisational intervention works (Abildgaard, Saksvik, \& Nielsen, 2016; De Looze, Vink, Koningsveld, Kuijt-Evers, \& Gu Van Rhijn, 2010). The concern is how an intervention process can be evaluated (Cox, Karanika, Griffiths, \& Houdmont, 2007; Nielsen \& Miraglia, 2017; Semmer, 2006) because intervention effectiveness is hard to assess (Cifre, Salanova, \& Rodríguez-Sánchez, 2011).

To gain a deeper insight into the intervention process, several scholars have called for the incorporation of process variables into the process evaluation (Dahler-Larsen, 2001; Pawson \& Tilley, 1997) of organisational interventions (Cox et al., 2007; Nielsen \& Abildgaard, 2013). Hasson et al. (2014) stated that process evaluation should include measurement of employee perceptions of exposure and intervention impact on several occasions during the intervention process. 
From the change management literature, we know that organisations consist of groups of actors with different horizontal functions and organisational boundaries, resulting in divergent viewpoints and perceptions of change (Eby, Adams, Russell, \& Gaby, 2000; Rafferty, Jimmieson, \& Armenakis, 2013). In order to consider divergent viewpoints and perceptions of change across groups of actors when measuring employee perceptions of intervention impact, we propose the use of a physical evaluation tool derived from the theory of boundary objects. The theory states that boundary objects are a physical means of converting knowledge that can cross the boundaries among multiple social worlds and can be used within and be adapted to many of them simultaneously (Carlile, 2002; Star \& Griesemer, 1989).

The aim of this paper is thus to explore intervention participants' continuous use and adaption of a physical evaluation tool (i.e. a boundary object) as a means to gain insight into the participants' perceived impact of an intervention process targeting the sources of workplace stress (i.e. organisational-level intervention). The study focuses on the design characteristics, evaluation process, perceived impact and employees’ experiences with the tool. Three Danish small- and medium-sized enterprises (SMEs) participated in the case study: (1) a software development company (IT), (2) a surveyor and software development company (IT) and (3) an assembly line for a manufacturing company. The application is part of a larger case study of preventive organisational-level interventions in SMEs (reference omitted).

\section{LITERATURE REVIEW}

\subsection{Process evaluation of interventions}


The need for assessing perceived impact during interventions is an important topic for investigation, and scholars in organisational interventions have called for additional research into how intervention impact can be evaluated. Intervention study researchers have focused mainly on outcome evaluation to establish whether the intervention had any effect (Lamontagne, Keegel, Louie, Ostry, \& Landsbergis, 2007). Applied psychology is the outset for outcome evaluations in primary interventions, however, Cox et al. (2007) argued that applied psychology’s traditional experimental approach is inadequate because it does not capture organisations' continuously changing complexity. The outcome evaluation provides information regarding whether the intended changes have had an effect, but it does not provide information about how and why the intervention succeeded or failed. The need for a process evaluation is thus suggested to serve as a supplement to gain additional knowledge about the intervention and its mode of action (Cox et al., 2007; Nielsen, 2013).

To gain a deeper insight into the intervention process, several scholars have called for the incorporation of process variables into the process evaluation (Dahler-Larsen, 2001; Pawson \& Tilley, 1997) of organisational interventions (Cox et al., 2007; Nielsen \& Abildgaard, 2013). In addition, Hasson et al. (2014) stated that process evaluation should include measurement of employee perceptions of exposure and intervention impact on several occasions during the intervention process.

Steckler and Linnan (2002) defined process evaluation as a "focus on the extent to which the intervention was implemented with the content, accuracy, coverage and quality that was planned". This strict focus on the intervention, particularly on its components and outcome, limits our understanding of the social mechanisms that are at work in organisations, including autonomy in decision-making (Kompier, Cooper, \& Geurts, 2000). To get insight into what works in 
interventions (Nielsen et al., 2010), researchers in occupational health therefore focus both on the social mechanisms and the intervention components and outcome (Bauer \& Jenny, 2013).

To minimise the gap between the planned and the actual implementation, Dahler-Larsen (2001) formulated Programme Theory in which stakeholders continuously evaluate the outcomes of an intervention. In line with Dahler-Larsen, Greene (1997) states that the results of an evaluation or intervention are more likely to be used if the users, through their participation, have invested in the process, creating a sense of ownership and commitment. To secure commitment, DahlerLarsen (2001) further suggests that participants decide on their programme goals and theory, which they can evaluate throughout the intervention. The aim of the evaluation is to gain increased insight into which factors are important for securing the expected outcomes; participants can respond to this and develop a new theory of how the goal can be met, thereby increasing the chances of success (Dahler-Larsen, 2001). In addition, according to Nielsen (2013), "more advanced measures of the process throughout the different phases of an organisational intervention may help researchers to distinguish between theory and programme failure and at which point the failure occurred" (p. 1044).

In conclusion, participation in process evaluation is one key to success because it creates ownership and commitment. Another key is to evaluate an intervention throughout the process, thus gaining insight into the outcomes and mechanisms that ensure the intended outcome as well as the influence of context on the mechanisms. Applying the conceptualisation of process evaluation opens up an approach based on continuous learning and reflection instead of just reporting the outcome retrospectively. The questions that remain are how this knowledge can be externalised and shared in a participatory intervention and how it can contribute to achieving the aim of the interventions. 


\subsection{Boundary objects}

This study refers to the understanding introduced by Star and Griesemer (1989) of a "boundary object" that can cross the boundaries of, be used within and be adapted to multiple social worlds simultaneously while also being adapted to local needs and the constraints of the parties employing it. Robust enough to maintain a common identity across sites (Star \& Griesemer, 1989), a boundary object is regarded as key in developing and maintaining coherence across intersecting social worlds and can be used as a means of representing, learning about and converting knowledge. In addition, a boundary object can support the transfer of knowledge across boundaries and enable the externalisation of tacit knowledge (Carlile, 2002) because it establishes a shared context for managing knowledge across a given boundary (e.g. a group of actors with different organisational boundaries) or supports learning processes (Seim, Broberg, \& Andersen, 2014). Boundary objects can be categorised into four types: (1) standardised forms and methods; (2) objects, models and maps; (3) discourses; and (4) processes (Broberg, Andersen, \& Seim, 2011). The physical evaluation tool in this study represents the second type of boundary object. In participatory ergonomics, examples of “objects, models and maps” include prototypes, mock-ups, fish-bone charts and bulletin boards.

To make a boundary object recognisable to different groups and capable of serving as a means of communication across boundaries (Star \& Griesemer, 1989), there must be sufficient convergence of meaning. To ensure the effectiveness of the boundary object, meaning should be negotiated among the participants (Carlile, 2002); in return, reconciled meanings and shared understanding will enable actors from different social worlds to cooperate (Bechky, 2003). 


\subsection{Knowledge conversion between tacit and explicit knowledge}

The evaluation tool object offers a context in which individual knowledge about the intervention impact can be externalised and become shared knowledge in a participatory process that creates a temporary learning space (Broberg et al., 2011). Acting as a boundary object, the evaluation tool facilitates dialogue and combines the individual knowledge of impact perception into shared explicit knowledge. The combined knowledge expresses the present status of the intervention. Thus, a collective evaluation tool bridges the stages of the knowledge-creation processes, which, in this case, is the individual's perception of intervention impact.

An organisation creates knowledge through interactions between tacit and explicit knowledge (Nonaka, 1994) that constitute a continuum (Nonaka \& von Krogh, 2009). Nonaka, Toyama, and Konno (2002) called the interaction between the two types of knowledge "knowledge conversion”, and they called the process whereby new knowledge is created using existing knowledge assets through the conversion of tacit and explicit knowledge the "SECI process". The SECI process features four modes of knowledge conversion:

- Socialisation: from tacit collective knowledge to tacit individual knowledge

- Externalisation: from tacit individual knowledge to explicit individual knowledge

- Combination: from explicit individual knowledge to explicit collective knowledge

- Internalisation: from collective explicit knowledge to tacit collective knowledge (Nonaka et al., 2002)

Knowledge conversion is context specific in terms of who participates and how. Consequently, each mode of knowledge conversion has a corresponding context or shared space, termed $b a$, which facilitates the knowledge-creation process. Examples of physical tools to improve the tacitto-explicit conversion process in a shared space include knowledge exchange protocols as used in 
the physician/patient clinical encounter (Herschel, Nemati, \& Steiger, 2001) or groupware-, workflow- and knowledge-based systems or knowledge portals in knowledge-intensive work (Carvalho \& Ferreira, 2001).

Building on a study of how to prevent stress in knowledge-intensive work (Ipsen \& Jensen, 2012), we chose to focus on the externalisation mode and combination mode in the SECI process. The study shows that workplaces have tacit individual knowledge of work-related problems and potential solutions but limited possibilities for the reflection required for individual knowledge to be externalised and shared collectively (i.e. combined) (Ipsen \& Jensen, 2012).

Corresponding to externalisation and combination of knowledge are the dialoguing $b a$ and the systemising $b a$, which are both designed by means of collective interactions. The dialoguing $b a$ offers a shared space for the externalisation of tacit individual knowledge, whereas the systemising $b a$ mainly offers a shared space in which to combine existing explicit knowledge, as explicit knowledge can be relatively easily transmitted to a large number of people in a tangible form (Nonaka et al., 2002). Although each $b a$ offers a space for a specific step in the knowledge-creating process, each also requires a medium where knowledge is shared through physical objects, such as books, manuals, memos, e-mails and teleconferences (Nonaka et al., 2002), which act as a framework for interaction among the participants.

Following the theories of process evaluation, boundary objects and knowledge-conversion processes, we aim to explore the use and adoption of a physical evaluation tool (i.e. a "visualisation object”), as well as how to convert knowledge (i.e. perceived impact) across the boundaries between multiple social worlds continuously through a process evaluation.

\section{METHODS}


To date, researchers have developed and introduced various methods for evaluating interventions, but the longitudinal randomised controlled trial is often the preferred method (Murphy \& Sauter, 2003; Nielsen \& Miraglia, 2017). We chose to conduct a qualitative exploratory case study (Bryman, 2004; Yin, 2009) for two reasons: First, we aimed to take into consideration that organisations consist of groups of actors with different horizontal functions and organisational boundaries and thus have divergent viewpoints and perceptions of change (Eby et al., 2000; Rafferty et al., 2013). Second, we focused on how to evaluate individual perceptions of intervention impact across different groups during an intervention.

This exploratory case study was designed to investigate the phenomenon of continuous evaluation in a participatory process by applying a physical tool with the intended function to explicate the knowledge of participants' perception of progress and impact across the three cases. The aim of our study was thus to explore the following:

- What are the design characteristics of the evaluation tool (i.e. the visualisation object)?

- What characterises the continuous evaluation process when applying a visualisation object as part of an organisational-level intervention?

- What does the continuous evaluation show regarding the perception of the intervention impact?

- What are the participants' experiences regarding the visualisation object?

\subsection{Study design}

The two-year qualitative study of three SMEs followed a case study design. Managers and employees participated in the intervention by applying the Prevention of Work Related Stress (PoWRS) programme (reference omitted) over a six-month period in a participatory fashion. 
Although the programme activities were fixed, the content was adapted to the worksite/workplace context and the interests of managers and employees. The key intervention components comprised a FishBone workshop (reference omitted) and a Kick-Off event (reference omitted), followed by the implementation and evaluation of the agreed-upon changes in work practices. In addition, ongoing steering and reference committee meetings were held to monitor the progress of the changes. (A detailed presentation of the intervention can be found in reference omitted.)

To gain insight into the participants' use and adaption experiences with the visualisation object, we conducted semi-structured interviews, observations and chronicle workshops (CWs) (Limborg \& Hvenegaard, 2011; reference omitted), followed by a cross-case analysis (Miles, Huberman, \& Saldana, 2014). Data collection was conducted eight times during the intervention period of six to nine months.

\subsection{Research context}

\subsubsection{Case selection and characteristics}

Knowledge-intensive SMEs in Denmark are experiencing increasing problems with work-related strain and stress, and work-related stress today is considered to be just as hazardous as accidents at the workplace (European Agency for Safety and Health at Work, 2010). The present study tested the PoWRS programme (reference omitted) and involved three case companies with no in-house support functions to facilitate preventive interventions. The case companies were Danish knowledge-intensive SMEs (Alvesson, 2004): Company 1, a software development company (IT); Company 2, a surveyor and software development company (IT); and Company 3, an assembly line at a manufacturing company. 
The first part of the project involved selecting case companies where we called for participants via LinkedIn, research contacts and workers' unions and managers' unions, i.e. SMEs with no inhouse support functions to facilitate preventive interventions. Among the available companies, the three case companies were selected based on their motivation for joining the project. All three acknowledged the need to act preventively on work-related stress and strain focusing on the work processes as the source for prevention, including the consideration of both productivity and prevention of stress offered by the PoWRS programme.

Company 1, a small software company that develops programmes for the tele-industry, consists of two departments, a larger development department of young developers and a smaller support section supporting customers experiencing problems with the developed software systems. The company chose two changes to be implemented—(1) project management, and (2) feedback and recognition—and involved those changes in feedback between project members, development of project start-up checklists, an overview of projects and their statuses and inclusion of people from the support section in the project team from the beginning to improve knowledge sharing and reduce failures. The participants applied the visualisation object every second week, but only one change was evaluated per month.

Company 2, a medium-sized surveyor and software development company (IT), consists of three departments at three different locations in Denmark. Experiencing stress and frustrations with the quality management of the tools and processes, the billing of hours and the time wasted, the employees chose to work with the following changes: (1) well-defined tasks, and (2) collegiate spirit and feedback. The intervention mainly involved changes in knowledge-sharing activities in the form of developing a wiki to share knowledge, improving project specifications, aligning expectations regarding project content and providing feedback. After a delayed start, the 
participants applied the visualisation object every second week, but only one change was evaluated per month.

Company 3, a medium-sized manufacturer of conveyer belts, has an assembly line division composed of two departments that are separated by a floor-to-ceiling storage shelf. Experiencing problems with daily management and planning, collaboration across subdivisions and tone of voice, the employees chose to work with (1) more cooperation and team spirit, and (2) visible and consistent management. In Company 3, the intervention included changes in the division manager's behaviour and presence, as well as joint activities to gain increased understanding and acceptance of personal differences and reactions during times of high workload, for example. The participants applied the visualisation object every second week, but only one change was evaluated per month.

Table 1 provides an overview of the selected company characteristics of the three study sites. In the smallest company, Company 1, the whole company participated, whereas in Company 2 and Company 3, just two and three departments, respectively, participated. In the selected departments, all employees and managers participated.

\section{[Insert Table 1]}

\subsubsection{The intervention programme}

As an organisational-level intervention, the PoWRS programme focused on changing work processes. The aim of the programme was to engage both employees and managers in a participatory design of the organisational intervention and related activities to address work-related topics and concerns (Jensen, 2001) that the participants found important and where change would support both productivity and well-being (reference omitted). Building on a participatory and 
multilevel principle also ensures that employees have a strong voice in the process (Hasle \& Zwetzloot, 2011).

The PoWRS programme comprises three phases and a set of activities in which both employees and managers participate step by step to explore their workplace. In collaboration, they evaluate and redesign their work practices and organisational design and then implement change.

Phase 1 comprises an assessment of the need for a primary intervention at the workplace to ensure support from top management and allocation of resources. In Phase 2, employees and managers explore their work and workplace by conducting two FishBone Workshops (Sørensen \& Holman, 2014), one for employees and one for managers, followed by a thematisation of the statements. The outcome of the two workshops is an overview of the working conditions that excite and stress employees in their work. Immediately following the FishBone Workshops, a "multivoting” session is initiated to prioritise the themes just identified. When the final top two changes are selected, the intervention is marked with a Kick-Off event to ensure collective attention and awareness about the intervention. Phase 3 concerns the systematic implementation of the organisational-level changes and the continuous evaluation and adjustment of the supporting activities. It is vital that everyone participates and that the changes are integrated into existing activities at the workplace. The implementation of the changes and supporting activities are company specific, and the outcomes are incremental changes regarding the working conditions identified during the FishBone Workshop, creating either (more) enthusiasm or (less) strain. After six months, the intervention terminates with the expected outcome that the organisational-level changes have been implemented as part of the daily activities.

According to Bauer and Jenny (2013), there are three approaches to organisational interventions: universalistic, contingency and configurational. The PoWRS programme takes the 
configurational approach, where the organisation is used as the target and actor of change, the implementation process is co-created and the intervention content is both predefined (i.e. programme activities) and emergent (i.e. activities initiated by the participants) (Bauer \& Jenny, 2013; Nielsen et al., 2010).

Regarding the intervention process, we know from the field that typically the process and content of intervention programmes are based on three principles: (1) participation, (2) management support and (3) intervention fit. The programmes are designed as phase models like the five-phase model by Nielsen et al. (2010), which is based on an in-depth review of organisational interventions. The key phases are as follows: Phase 1, initiation; Phase 2, screening; Phase 3, action planning; Phase 4, implementation (monitoring and communication); and Phase 5, evaluation (process and effect evaluation) (Nielsen \& Noblet, 2018). The PoWRS programme embraces and condenses all five of Nielsen's phases into three phases in which Phase 1 concerns initiation, Phase 2 concerns screening and action planning and Phase 3 includes both implementation and evaluation.

The FishBone Workshop revealed work-related problems such as misalignment of tasks, lack of recognition and feedback, lack of internal communications and imbalance between tasks and time. In the voting process, the managers and employee chose these changes: (1) project management, (2) feedback and recognition, (3) well-defined tasks, (4) collegiate spirit and feedback, (5) more cooperation and team spirit and (6) visible and consistent management.

A Kick-Off event marked the start of the implementation of the chosen activities. (For an overview of the changes and their supporting activities, see Table 2.) In the following four to five months, employees and managers implemented the agreed work-related changes (two changes in each company). During the intervention process, the employees evaluated the intervention's 
progress and outcome by applying the physical evaluation tool to assess their perception of the intervention impact. The intervention ended after six months.

[Insert Table 2]

\subsection{Data collection}

The research team acted as supervisors during the intervention, but they did not participate in the companies' daily operations or in the implementation of the changes. The research team conducted four rounds of semi-structured interviews (see Table 3).

[Insert Table 3]

The interview guide focused primarily on gaining information about the evaluation tool (Design Characteristics), the participants' experiences with the continuous use and adaption of the physical evaluation tool during the intervention process to assess their perception of the intervention impact (Evaluation Process) and the employees' and managers' perception of the impact (Impact).

Besides interviewing programme participants, the research team also followed the intervention process in the three companies by observing the planned programme activities and the progression of the interventions during four on-site visits. The team documented its observations via handwritten notes and photos. In each CW (Limborg \& Hvenegaard, 2011), the following question provided insight into the role of the visualisation object (reference omitted): Which factors have had an impact on the interventions?

The overall principle behind the CW evaluation tool is to map the participants' viewpoints and create a space via paper on the wall and post-it notes in which the participants' narratives get an equal voice. The CW's three questions work as a funnel, where the first question gives each of the 
participants the opportunity to mention whatever they remember from the past six months. It also gives an indication of whether the intervention had settled itself as an independent event. The following was the first question asked in the CW: Which important changes have occurred during the past six months that have affected your work? The outcome is a timeline presenting the main events during the studied period. The second question provides information about what the participants actually remembered as part of the intervention: Which important changes in your work have you discovered in relation to the intervention? The third question reveals obstacles and drivers for the intervention: Which factors have impacted the interventions? The answers for questions 2 and 3 are mapped on the timeline. The outcome of the CW is a summary view of intervention-related results and influencing factors (reference omitted).

The post-intervention survey consisted of 15 questions focusing on the intervention process, progress and outcome. It included the following question on a three-point Likert scale about the application of the visualisation object and the ongoing evaluation: What importance do you attach to the visualisation and the continuous assessment of the intervention?

\subsection{Coding and data analysis}

Data from interviews, photos of the visualisation objects from each site visit and the CW were analysed using a conceptually clustered matrix (Miles et al., 2014). The interview data were transcribed and uploaded into NVivo. Descriptive coding was applied during the first coding cycle (Hasson, von Thiele Schwarz, Nielsen, \& Tafvelin, 2016) with a focus on the themes of design characteristics of the visualisation object, the participants' application of the visualisation object (process characteristics) and the participants' perception of impact. The data used to analyse the 
design characteristics included the observations and photos. Table 4 presents the codes from the first and second coding cycles.

[Insert Table 4]

In the second coding cycle, the summarised data from the first cycle were grouped into fewer themes. The cross-case analysis was used to identify common characteristics of the visualisation object and the evaluation process. Finally, to validate the qualitative data, we used one question from the completion survey (see section 3.3). The conceptually clustered matrix method was applied again to data from the interviews, the CW and the completion survey to identify participants' experiences (themes) with the visualisation object across the three cases.

\section{RESULTS}

The results begin with a detailed description of the design characteristics of the participating companies' visualisation objects. We then describe the evaluation process characteristics. Finally, we present the participants’ experiences of applying the visualisation object.

\subsection{Design characteristics of the visualisation object}

In all three companies, the in-house facilitators chose the materials and layout for the visualisation object, which resulted in three different designs (see Figure 1a-d).

[Insert Figure 1a] [Insert Figure 1b] [Insert Figure 1c] [Insert Figure 1d]

In Company 1, the facilitators asked all participants to decorate their own component in the form a wooden brick as part of the Kick-Off event. To identify each evaluation component, the inhouse facilitators in all three companies decided whether the components should carry the initials of the participants or a just a number. Regarding the unit of evaluation, the companies chose to 
apply either a two- or three-point scale. Finally, the facilitators, together with their managers, decided where to place the visualisation object. All three companies chose areas that were accessible and visible (see Table 4).

\subsection{Characteristics of the evaluation process}

In each of the three case companies, the facilitators and manager decided to conduct monthly evaluations for each change (see Table 4). Implementing two changes in each company resulted in an evaluation every second week. The employees conducted the evaluations together at department meetings or when possible (Company 2), and each employee reflected on the following question: Regarding the XX change, have I experienced any progress since the start/since the last evaluation? Their individual perceptions and answers to this question were then marked on the visualisation object. When all employees had evaluated the intervention, the visualisation object showed an overall visual status of the intervention at that point in the process.

In Company 1, the facilitators found a way to remind their colleagues to use the visualisation object. Every second week, the facilitators removed all the wooden bricks with the employees’ initials from the visualisation object, demonstrating who had not yet evaluated the change. Companies 1 and 3 evaluated the changes from the beginning. In Company 2, however, the visualisation object was developed and applied only halfway through the intervention, when the

project team realised the need for more employee involvement to gain more feedback on the intervention progress and outcome.

\subsection{Participants' perception of intervention impact by means of the visualisation object}

\subsubsection{Company 1}


Company 1 began to evaluate the progress of its two changes just after the Kick-Off event, without the presence of the research team. Company 1 operated with a scale of two evaluation units: "progress" and "status quo". The data from the first interview round show that the majority of employees in Company 1 applied the unit "status quo".

In the second round, the participants in Company 1 still applied the visualisation object and evaluated the changes every other week. At this point, Company 1 had experienced progress regarding the change called "better project management" where the majority of the employees had evaluated "progress" on the visualisation object. Regarding the change "feedback", the employees had experienced very little progress, so the majority had placed their evaluation component on the unit "status quo".

During the last visit to Company 1, the visualisation object showed that the majority of participants had the perception that the "project management" change had improved and the intervention had progressed. The change relating to "feedback" had made only a little progress since the second follow-up. Figure 2 is a graphical illustration of the differences in progress of the two changes in Company 1.

\section{[Insert Figure 2 here]}

\subsubsection{Company 2}

At the first follow-up, the first round, Company 2 had not yet started the evaluation process because the top manager had decided against using the ongoing evaluation, and, therefore, no one had chosen a design for the visualisation object. At the second round, however, we realised the director and facilitators had recognised the need for an ongoing evaluation of the intervention. Therefore, each of the three participating departments had designed an individual visualisation object (see 
Figure 1b and 1c). Employees who worked at many different locations evaluated the intervention at department meetings or when they were back in the office.

In Company 2, two of the department's visualisation objects showed limited change, and less than half of the employees had evaluated the changes. In the third department, the employees were actively using the visualisation object, and the intervention had resulted in work-related changes such as new knowledge-sharing processes to ensure well-defined tasks (Change 1). The completion survey showed that the majority (64.3\%) of the respondents found the evaluation and visualisation object had little or no importance (see Table 5).

\subsubsection{Company 3}

At the first follow-up meeting, Company 3 applied three units on their scales—“worsened", "status

quo" and "progress"- but only a few employees had experienced a positive change since the KickOff event (Figure 3a). During the intervention, the visualisation object showed little progress regarding the changes called "more cooperation and team spirit" and "visible management" (Figure 3b).

[Insert Figure 3a] [Insert Figure 3b]

The participants also discussed the three response units and decided to apply only two of them, leaving out the middle unit of "status quo", which was evidenced during our last visit to Company 3. The majority of the employees had experienced progress regarding both changes. The completion survey showed that the majority of the participants (66.7\%) found that the visualisation object had great importance for the intervention (see Table 5). 
In the CWs, where all workshop participants answered the same question (Which factors have had an impact on the interventions?), no one in any of the three companies mentioned the visualisation object.

\subsection{Participants' experiences with the visualisation object}

The completion survey showed that half of the participants found that the visualisation object had great importance for the intervention (see Table 5).

[Insert Table 5 around here]

Across the three companies, four themes emerged from the data regarding experiences with the visualisation object: (1) visibility, (2) signalling effect, (3) scale and unit and (4) subjectivity in the evaluation.

\subsubsection{Visibility}

The first theme, visibility, relates to the fact that the visualisation object is a way to see the progress of the intervention: "We could clearly see it on the ribbons related to the change 'visible management' that they [the employees] thought it was nice that they saw her [the manager] more often” (Facilitator, Company 3). A manager from Company 1 supported that statement: "I have been very happy that we evaluated continuously to see what happened. We were able to see that we did something, and the week after, five bricks had moved [to green].” At the same time, the visualisation object reminded the participants of the intervention. One of the facilitators from Company 3 had the following reflection: "I actually think it has a bigger importance than we reckon, because people see it." Some employees in Company 1 also acknowledged the value of visibility: "Every time we meet at the coffee machine and talk, it gives us some input; you have a pile of wooden bricks that reminds you [of the intervention] [. . . ]. Its presence matters.” However, 
in Company 2, it was not possible to place the visualisation object in a way that made it visible and accessible to every participant because the departments were located at different sites. The company's solution was to develop a visualisation object in each department.

\subsubsection{The signalling effect}

One employee perceived the application of the visualisation object as a statement from management conveying that employees' opinions were welcome. One employee in Company 1 stated, "It becomes an opportunity for people to express their opinions [...] no matter what $[\ldots]$ [the management] want to hear. That is important to me.” One first-line manager from Company 2 was conscious of the value of the visualisation object as an intervention progress evaluation tool; however, the manager acknowledged that it could act as a performance management tool.

\subsubsection{Scale and unit}

The application of the visualisation object also proved to be difficult in relation to its scale. The participants discussed the evaluation scales in terms of options: Should it include two or three units? What should each unit indicate? Some of the employees also expressed doubts about what the object actually evaluated. For example, in Company 1 , one of the changes concerned better project management, but what did better project management cover? The participants knew the current situation, but they did not know how to compare it with a future situation because the future state had not yet been defined. For example, how many project managers or project meetings were needed to improve the current situation?

\subsubsection{Subjectivity}

In relation to scale and unit, several participants explained that they were unsure about how the scales were defined and by whom. Their experience was that the evaluation was based on 
individual perceptions of progress, which raised the question of when one's experience of a change was sufficient to trigger progress, as well as questions concerning the impact of subjectivity in the evaluation.

\section{DISCUSSION}

This study brought together theories of knowledge conversion and boundary objects in relation to a preventive and participatory organisational intervention to allow intervention participants with different viewpoints and perspectives to engage in a shared knowledge conversion process (i.e. a process evaluation of an organisational intervention).

The results show that applying a boundary object in process evaluation can facilitate the externalisation and combination of individual knowledge and perceptions about the impact of an intervention. The study applied a tangible visualisation object (i.e. a boundary object) as an evaluation tool to facilitate the conversion of tacit individual knowledge about the perceived impact to externalised knowledge, which was then combined into explicit collective knowledge about the intervention's impact. We found that the three companies experienced the evaluation tool as creating a shared room for knowledge conversion about the participants' perceptions of impact. Thus, the results demonstrate that a tangible and visible evaluation tool can create a $b a$ for sharing knowledge about outcomes. The results also show that applying the evaluation tool can support the explication and combination of knowledge, thereby providing insights into the concrete progress of the intervention.

The boundary object (i.e. the visualisation object) therefore acts as the theory says it would act as participants' perceptions across groups become clear, explicit and shared. It thus forms the 
basis for convergence of participants' understanding of the intervention and compliance with the goal.

The evaluation tool consisted of two types of $b a$. The first $b a$ supported the externalisation of individual tacit knowledge about one’s personal perception of progress to explicit individual knowledge (the dialoguing $b a$ ). Here, all the participants reflected on the outcome of the intervention so far and answered the following question: Regarding the intervention, have I experienced any progress?

These individual answers (i.e. externalised individual knowledge) were then combined by and disseminated among the participants. The systemising $b a$ supported the combination of the new knowledge through application of the visualisation object. Here, all the participants made visible their perceived status of the outcome by entering their experience on the evaluation tool. When they had all evaluated the intervention, the visualisation object provided a visual status of the intervention outcome at that point in the process. Given these results, it is possible to propose that a visualisation object can act as a boundary object and create a shared space for knowledge conversion.

\subsection{Design of the visualisation object and the implementation process}

The results show that the companies designed different visualisation objects; ribbons, bricks and plastic balls, which is to be expected because the companies designed the visualisation objects based on their own ideas. Company 1 and Company 3 both applied the visualisation object throughout the intervention and had a similar evaluation process, whereas Company 2 began its evaluation process only midway through the intervention. The scales applied were also similar, although Company 3 began with three units that were then changed to two. 
This seems to indicate that when the participants design the object themselves, and both managers and employees take ownership of the process from the beginning, there is a higher probability of participation in the initiation phase, which supports a good start and the continuous evaluation of the intervention (Table 5). The results may also be due to the central location of the visualisation object and participation from all groups at each evaluation. Therefore, to create a shared commitment, the ideal is to have a single boundary object placed at a central spot in the workplace.

This is obviously a challenge at workplaces with distributed work areas, such as Company 2. Therefore, if departments pursuing the same goals are located at different sites, individual visualisation objects at each site are needed to create local ownership. To create shared ownership across all sites, the same base tool could be used across departments but with the option to apply different local features. Finally, note that the participants pointed at factors other than the visualisation object, i.e. effect modifiers (Edwards \& Winkel, 2018), as influencing the implementation process as the data shows from the CWs. This would suggest that the visualisation object was insignificant to the implementation. As each case company conducted the evaluation process as part of division meetings, it is not surprising that the use of the visualisation object did not stand out from other meeting activities and was not related specifically to the intervention.

Although the CWs did not show that the visualisation objects influenced the intervention process, the completion survey (see Table 5) shows that the majority of participants attached great importance to the visualised assessment of the intervention. The difference can be explained by the use of an explicit question about the visualisation object in the survey, as opposed to the CWs, where the questions do not refer directly to specific intervention activities. 


\subsection{Experiences with the visualisation object: A way to align expectations of changes and illustrate differences in momentum}

The evaluations in Company 1 and Company 3 showed slow progress towards change during the first months, with a greater increase at the end of the intervention. The interviews clearly show that the participants initially had different opinions and understandings about the purpose of the interventions and the evaluation scales. It was only during the intervention that the participants experienced a joint understanding of the purpose based on the continuous and collective dialogue facilitated by the visualisation object.

So far, intervention research has argued for alignment of the intervention goal and content between managers and employees in the early phases of organisational interventions (Star \& Griesemer, 1989). Although the participants in this study initially identified the intervention goal and content in collective and participatory processes, our results show that there are differences in the understanding of purpose and that an ongoing alignment of expectations and understanding among the participants is needed during the intervention process. Our research suggests that intervention researchers should be aware of this relationship and that a common identification of efforts does not necessarily ensure a common understanding of the intervention's purpose. Applying a boundary object is one way of aligning expectations.

Another surprising factor is the variation of momentum between two intra-organisational changes (see Figure 2). Thus, in Company 1, progress was not identical between the two changes "project management" and "feedback and recognition". The first change relates directly to work

processes, and the other relates to the relationships among the employees and managers. The interviews and CW pointed out that efforts and changes that implicate direct behavioural change are more difficult to implement than efforts related to work processes, which can explain the 
differences in momentum. This seems to indicate that researchers should be aware of the type of change when designing interventions, as behavioural changes are more difficult to implement and thus require more time. It also implies that while the motivation might be present, the ability to change behaviour is lacking, which can explain why the facilitators conducted different training exercises about feedback and recognition. Regarding evaluating a behavioural change over a longer period, there is a risk that the participants might lose interest in the visualisation object and thus reduce its effect as a reminder. In that case, another approach would be required to ensure the participants' attention and to facilitate the evaluation.

\subsection{Gains and challenges relating to the visualisation object}

The results of our study show that there are both gains and challenges in applying a visualisation object as part of an evaluation process. First, the respondents' perception of gains revolved around the visualisation object as an ongoing reminder of the intervention. The use of the evaluation tool provided collective insight into progress so that when changes occurred, they acted as a collective reminder of the intervention and the related changes. Second, the visualisation object facilitated a collective dialogue about the goal and how to assess a positive change and outcome, providing a converging understanding of the changes and intervention content. Acting as a boundary object, the evaluation tool facilitated the dialogue and combined the individual knowledge of perception of the impact into shared explicit knowledge about the present status of the intervention. Thus, the collective evaluation tool bridged the stages of the knowledge-creation processes, i.e. the participants’ individual perception of intervention impact.

Third, the study shows that the visuals are also objects that explicate opinions and perceptions because they facilitate a dialogue and the conversion of knowledge regarding the purpose and meaning of the intervention and its impact, which are not clearly defined from the beginning (as 
evident from the study), even though the changes are identified and formulated among the participants. In other words, the converging understanding can support the participants' aim for the same intervention goal as it creates an increased compliance among the participants about what is being changed.

Consequently, it can be difficult to talk about the intervention's effect and outcome if the intervention participants disagree. However, if compliance and internal agreement about the change can be achieved using a boundary object among the participants and across groups with different understandings and diversity, then it strengthens the opportunities for studies focusing on components and outcomes to draw stronger conclusions. If an intervention programme does not take these differences into consideration, it complicates the ability to come to conclusions regarding the effect.

In terms of the challenges, the participants pointed towards the meaning of the evaluation's outcome; how to define response categories, units and scales; accessibility; and anonymity. Some participants thus found it difficult to understand the evaluation process and make sense of the outcome, which became evident during the first two rounds of interviews where the participants across groups had different perceptions of the changes and the goal of the intervention.

Regarding the evaluation scale and units, we did not anticipate that quantifying personal experiences would be difficult. Nor did we foresee that the number of units would be a challenge. One reason for this could be that the visualisation objects were not acknowledged by all participants and therefore could not serve as a means of communication across boundaries, owing to insufficient convergence (Carlile, 2002) and lack of negotiation of meaning (Carlile, 2002; Star \& Griesemer, 1989) among the participants. We interpret the difficulties related to subjectivity, scale and unit as indicating a need for further negotiations among the different participants prior 
to implementing the changes. Another explanation of this challenge could be that the facilitators had designed the tools and then presented them to the rest of the participants. This confirms Green's (1997) argument that the results of an evaluation or intervention are more likely to be used if the users, through their participation, have invested in the process, thus creating a sense of ownership and commitment.

As the data shows, the participants in Company 1 were explicitly reminded to evaluate the change. An assumption could be that the participants would react to this. However, there is no evidence of negative reactions to the reminders. The data shows that missing the day of the evaluation was not an expression of lack of support or resistance towards the interventions but the effect of telework where employees had the opportunity to work from home, including days with division meetings when the evaluations took place. An interesting aspect of telework or distance work and the evaluation process of interventions that emerges is thus how changes can be implemented and evaluated in practice when managers and employees are not present at the workplace at the same time (Fisher \& Fisher, 2001). This raises the question of whether future intervention programmes and evaluation studies should take the implication of telework and distance work into consideration when designing intervention programmes and evaluations. Given that distance work often is virtual work where digital tools such as laptops and smartphones provide the basis for conducting the work (reference omitted), consideration should be given to whether and how physical visualisation objects can be used as an evaluation tool.

Distance work and interventions is definitely a challenge that may be met by using an online evaluation tool, for example, in the form of an app that constitutes an object, could facilitate the evaluation and still acts as a reminder of the intervention. However, to ensure the dialogue among the participants, it would require an online social platform where the participants could meet 
virtually. In cases where distance is not just a matter of geography but also time (e.g. time zone or work shifts), it would require a sequential use of the tool, and, consequently, a loss of commitment may occur.

Finally, we want to emphasise that the application of the visualisation object provides only a temporary insight into the impact and progress of intervention and does not provide insight into the mechanisms that lead to the impact. To gain insight into conditions affecting the intervention and the application of the visualisation object during the intervention process, the evaluations would benefit from an identification of causes or mechanisms. This is worth exploring further, and a suggested approach is to interview the participants about their perceptions of what works in the intervention and the conditions affecting the intervention.

\section{CONCLUSION}

This study attempted to explore intervention participants' continuous use and adaption of a physical evaluation tool (i.e. a boundary object) as a means to gain insight into the participants' perceived impact of an intervention process targeting the sources of workplace stress (i.e. organisational-level intervention). The study focused on the design characteristics, evaluation process, perceived impact and employees' experiences with the tool in three SMEs.

Based on a qualitative study in three workplaces - two in information technology (IT) and one in manufacturing, this study argues for viewing an intervention progress evaluation tool of participant perception as a boundary object. Boundary objects are physical means of converting knowledge that can cross the boundaries between multiple social worlds and can be used within and adapted to many of them simultaneously. The findings identify the following benefits of applying a tangible 
visual evaluation tool: (1) clarifies differences in perceptions of purpose and impact, (2) acts as a reminder of the intervention and (3) creates a sense of ownership.

Applying boundary objects in a continuous evaluation process can facilitate the externalisation of tacit knowledge about intervention outcomes. By encompassing knowledge conversion into the process evaluation, new knowledge is combined, shared and visualised through the visualisation object, which acts as a $b a$. By incorporating a knowledge conversion process (Fisher \& Fisher, 2001) with the application of boundary objects during the intervention process, participants can engage in a shared knowledge conversion process, or $b a$. In the process, the participants externalise tacit individual knowledge about the perceived impact of the intervention and combine it into explicit collective knowledge of the impact and progress.

This study found that the application of the visualisation object clarified that the participants initially had different understandings of the purpose of the intervention, despite its participatory formulation. Thus, the evaluation did not provide an accurate picture of the intervention's progress and impact because the participants experience the impact differently. Continuous use would allow the combined individual perceptions to provide a full picture of the impact and progress of the intervention at a certain point in time in the intervention process.

This study underlines the importance of including the participants' knowledge and perceived impact during the intervention and supports the value of applying a physical evaluation tool because it enables the participants to assess their perception of impact continuously and also explicates any potential differences in the understanding of the intervention's purpose. Such tools have the potential to be aligned through continuous use and to provide an accurate assessment of impact. 


\subsection{Recommendations}

In future development and adjustments of visualisation objects, we recommend the following:

(1) Consider (a) visibility, (b) signalling effect, (c) scale and unit, and (d) subjectivity in the evaluation and design of an efficient visualisation object.

(2) Include all participants in the choice of the object's design.

(3) Allow the participants to clearly formulate the goal for the specific change in the intervention, so that they know what to match the current situation with.

(4) Apply two clearly defined voting categories, and avoid a "neutral" voting option that allows participants to take the easy option.

(5) Respect local needs (e.g. the need for anonymity).

(6) Use a single boundary object for all worksites when all departments are located at the same site and people have physical access to the same place to create a shared commitment. However, if departments are located in different settings, each one should have its own visualisation object to create local ownership, even though all objects are used to pursue the same goals. The same tool could be used across departments but with different local features.

\subsection{Limitations}

A number of limitations should be noted. First, the development and the application of the PoWRS programme and visualisation object is a solely Danish study, and the results and conclusions may therefore apply only in a Danish context. Second, the number of cases is limited, and it can be difficult to make comparisons across three companies as well as to identify which specific components of the tool impacted the process. For future studies, we recommend applying the 
visualisation object in an adequate number of similar workplaces to make a more thorough comparison. A third limitation regards the length of the intervention and the research teams' follow-up meetings. Company 1 began before the other companies and initiated the process before the summer holidays, giving it 10 more weeks between the Kick-Off and the first follow-up meeting than Companies 2 and 3. This may have affected the progress that was detected.

\section{Funding sources}

This work was supported by the Danish Work Environment Research Foundation (grant number 132009-03).

\section{REFERENCES}

Abildgaard, J. S., Saksvik, P., \& Nielsen, K. (2016). How to measure the intervention process? An assessment of qualitative and quantitative approaches to data collection in the process evaluation of organizational interventions. Frontiers in Psychology. https://doi.org/10.3389/fpsyg.2016.01380

Alvesson, M. (2004). Knowledge work and knowledge-intensive firms (Vol. 1). New York, NY: Oxford University Press.

Bauer, G., \& Jenny, G. (2013). Salutogenic organizations and change. The concepts behind organizational health intervention research (Vol. 1). Dordrecht, Netherlands: Springer. https://doi.org/10.1007/978-94-007-6470-5

Bechky, B. A. (2003). Sharing meaning across occupational communities: The transformation of understanding on a production floor. Organization Science 14(3). https://doi.org/10.1287/orsc.14.3.312.15162

Broberg, O., Andersen, V., \& Seim, R. (2011). Participatory ergonomics in design processes: 
The role of boundary objects. Applied Ergonomics, 42(3), 464-472.

https://doi.org/10.1016/j.apergo.2010.09.006

Bryman, A. (2004). Social research methods (Vol. 2). Oxford, England: Oxford University Press.

Carlile, P. R. (2002). A pragmatic view of knowledge and boundaries. Organization Science, 13 (4), 442-455.

Carvalho, R., \& Ferreira, M. (2001). Using information technology to support knowledge conversion processes. Information Research, 7(1).

Cifre, E., Salanova, M., \& Rodríguez-Sánchez, A. M. (2011). Dancing between theory and practice: Enhancing work engagement through work stress intervention. Human Factors and Ergonomics in Manufacturing 21 (3). https://doi.org/10.1002/hfm.20232

Cox, T., Karanika, M., Griffiths, A., \& Houdmont, J. (2007). Evaluating organizational-level work stress interventions: Beyond traditional methods. Work \& Stress, 21(4), 348-362.

Dahler-Larsen, P. (2001). From programme theory to constructivism. Evaluation, 7(3), 331.

De Looze, M. P., Vink, P., Koningsveld, E. A. P., Kuijt-Evers, L., \& Gu Van Rhijn, J. W. (2010). Cost-effectiveness of ergonomic interventions in production. Human Factors and Ergonomics in Manufacturing, 20 (4). https://doi.org/10.1002/hfm.20223

Eby, L. T., Adams, D. M., Russell, J. E. A., \& Gaby, S. H. (2000). Perceptions of organizational readiness for change: Factors related to employees’ reactions to the implementation of team-based selling. Human Relations, 53(3), 419-442. https://doi.org/10.1177/0018726700533006

Edwards, K., \& Winkel, J. (2018). A method for effect modifier assessment (EMA) in ergonomic intervention research. Applied Ergonomics 72. https://doi.org/10.1016/j.apergo.2018.05.007 
Elkin, A. J., \& Rosch, P. J. (1990). Promoting mental health at the workplace: The prevention side of stress management. Occupational Medicine: State of the Art Review, 5, 739-754.

European Agency for Safety and Health at Work, 2010.

Fisher, K., \& Fisher, M. D. (2001). The distance manager. A hands-on guide to managing offsite employees and virtual teams. New York, NY: McGraw-Hill.

Greene, J. C. (1997). Participatory evaluation. In L. Mabry (Ed.), Advances in program evaluation (pp. 171-189). Greenwich, CT: JAI Press.

Hasle, P. \& Zwetzloot, G. (2011). Editorial: Occupational Health and Safety Management Systems: Issues and Challenges. Safety Science, 49, 961-963. https://doi.org/10.1016/j.ssci.2011.02.013

Hasson, H., Brisson, C., Guérin, S., Gilbert-Ouimet, M., Baril-Gingras, G., Vézina, M., \& Bourbonnais, R. (2014, May). An organizational-level occupational health intervention: Employee perceptions of exposure to changes, and psychosocial outcomes. Work \& Stress 28 (2), 1-19.

Hasson, H., von Thiele Schwarz, U., Nielsen, K., \& Tafvelin, S. (2016). Are we all in the same boat? The role of perceptual distance in organizational health interventions. Stress and Health 32(4). https://doi.org/10.1002/smi.2703

Herschel, R. T., Nemati, H., \& Steiger, D. (2001). Tacit to explicit knowledge conversion: Knowledge exchange protocols. Journal of Knowledge Management, 5(1), 107-116. https://doi.org/10.1108/13673270110384455

Reference omitted

Reference omitted

Reference omitted 
Ipsen, C. \& Jensen, P.L. (2012). Organizational options for preventing work-related stress in knowledge work. International Journal of Industrial Ergonomics, 42(1), 325-334. https://doi.org/ 10.1016/j.ergon.2012.02.006

Jensen, P. L. (2001). Risk assessment: A regulatory strategy for stimulating working environment activities? Human Factors and Ergonomics in Manufacturing, 11(2), 101-116. https://doi.org/10.1002/hfm.1002

Kompier, M., Cooper, C., \& Geurts, S. A. E. (2000). A multiple case study approach to work stress prevention in Europe. European Journal of Work and Organizational Psychology, 9(3), 371.

Kompier, M., \& Kristensen, T. S. (2000). Organizational work stress interventions in a theoretical, methodological and practical context. In J. Dunham (Ed.), Stress in the workplace: Past, present and future (pp. 164-190). Philadelphia, PA, US: Whurr Publishers.

Lamontagne, A. D., Keegel, T., Louie, A. M., Ostry, A., \& Landsbergis, P. A. (2007). A systematic review of the job-stress intervention evaluation literature, 1990-2005. International Journal of Occupational and Environment Health, 13(1), 268-280.

Limborg, H. J., \& Hvenegaard, H. (2011). The chronicle workshop. In L. Rasmussen (Ed.) Facilitating Change (1st ed., pp. 305-327). Kgs. Lyngby, Denmark: Polyteknisk Forlag. Mellor, N., Mackay, C., Packham, C., Jones, R., Palferman, D., Webster, S., \& Kelly, P. (2011). "Management standards” and work-related stress in Great Britain: Progress on their implementation. Safety Science, 49, 1040-1046.

Miles, M. B., Huberman, A. M., \& Saldana, J. (2014). Qualitative data analysis: A methods sourcebook. Thousand Oaks, CA: Sage. https://doi.org/10.1080/0140528790010406 
Murphy, L. R. (1988). Workplace interventions for stress reduction and prevention. In C. L. Cooper \& R. Payne (Eds.), Causes, coping and consequences of stress at work (pp. 301339). Chichester, England: Wiley.

Murphy, L. R., \& Sauter, S. L. (2003). The USA perspective: Current issues and trends in the management of work stress. Australian Psychologist, 38(2), 151-157.

Nielsen, K. (2013). How can we make organizational interventions work? Employees and line managers as actively crafting interventions. Human Relations, 66(8), 1029-1050.

Nielsen, K., \& Abildgaard, J. S. (2013). Organizational interventions: A research-based framework for the evaluation of both process and effects. Work \& Stress, 27(3), 278-297.

Nielsen, K., \& Miraglia, M. (2017). What works for whom in which circumstances? On the need to move beyond the "what works?" question in organizational intervention research. Human Relations, 70(1), 40-62. https://doi.org/10.1177/0018726716670226

Nielsen, K., \& Noblet, A. (Eds.). (2018). Organizational interventions for health and well-being. A handbook for evidence-based practice.. New York, NY: Routledge.

Nielsen, K., Raymond, R., Holten, A.-L., \& González, E. R. (2010). Conducting organizationallevel occupational health interventions: What works? Work \& Stress, 24(3), 234-259.

Nonaka, I. (1994). A dynamic theory of organizational knowledge creation. Organization Science, 5(1), 14-37.

Nonaka, I., Toyama, R., \& Konno, N. (2002). SECI, ba, and leadership. In I. Nonaka \& D. Teece (Eds.), Managing industrial knowledge: Creation, Transfer and utilization (pp. 13-43). London, UK, SAGE Publications Ltd.

Nonaka, I., \& von Krogh, G. (2009). Perspective-tacit knowledge and knowledge conversion: Controversy and advancement in organizational knowledge creation theory. Organization 
Science, 20(3), 635-652. https://doi.org/10.1287/orsc.1080.0412

Pawson, R., \& Tilley, N. (1997). Realistic evaluation. London, England: SAGE Publications Ltd. Reference omitted

Rafferty, A. E., Jimmieson, N. L., \& Armenakis, A. A. (2013). Change readiness: A multilevel review. Journal of Management, 39(1), 110-135. https://doi.org/10.1177/0149206312457417

Seim, R., Broberg, O., \& Andersen, V. (2014). Ergonomics in design processes: The journey from ergonomist toward workspace designer. Human Factors and Ergonomics in Manufacturing, 24(6), 656-670. https://doi.org/10.1002/hfm.20508

Semmer, N. K. (2006). Job stress interventions and the organization of work. Scandinavian Journal of Work Environment Health, 32(6), 515-527.

Sørensen, O. H., \& Holman, D. (2014). A participative intervention to improve employee wellbeing in knowledge work jobs: A mixed methods evaluation study. Work \& Stress, 28(1), 67-86. https://doi.org/10.1080/02678373.2013.876124

Star, S. L., \& Griesemer, J. R. (1989). Institutional ecology, "translations" and boundary objects: Amateurs and professionals in Berkeley's Museum of Vertebrate Zoology, 1907-39. Social Studies of Science 19(3), 387-420.

Steckler, A., \& Linnan, L. (Eds.). (2002). Process evaluation for public health interventions and research (1st ed.). San Fransisco, CA: Jossey-Bass.

Westgaard, R. H., \& Winkel, J. (2011). Occupation musculoskeletal and mental health:

Significance of rationalization and opportunities to create sustainable production systems: A systematic review. Applied Ergonomics, 42, 261-296.

Yin, R. K. (2009). Case study research: Design and methods. Essential guide to qualitative 
methods in organizational research (Vol. 5). SAGE

https://doi.org/10.1097/FCH.0b013e31822dda9e 